\title{
A Complicated Case of Foreign Body Oesophagus in an Infant
}

Arvind Kumar Verma', Ruma Guha', Chiranjib Das ${ }^{1}$, Saumendra Nath Bandyopadhyay²

Introduction

\section{ABSTRACT}

A case of a one year child with accidental ingestion of a safety pin is reported.

Case Report

A broken safety pin with missing clip was found impacted in the upper oesophagus with both ends pointing upwards. It was

removed by rigid oesophagoscopy.

Discussion

Sharp foreign bodies have increased risk of complication.

Conclusion

Improvisations are often required in the surgical technique to tackle difficult situations.

$\underline{\text { Kevwords }}$

Foreign Bodies, Esophagoscopy, X-Rays, Child

I ngestion of foreign bodies is common primarily in children, psychiatric patients, alcoholics and elderly people who use dentures. ${ }^{1,2,3}$ Selivanov et al. reported that, in most cases of foreign body ingestion, the most common foreign bodies ingested were coins, bones, food debris, safety pins and razor blades. ${ }^{4}$

We report a case of a one year child presenting to us with accidental ingestion of a safety pin. Rarity, technical difficulty in removing the foreign body, complications associated with the delay in diagnosis and treatment, migration of the foreign body extraluminally, site, shape and position of the sharp end of a safety pin makes this case interesting and worth reporting. The case was difficult because the protected end of the safety pin was broken which made both the ends of the foreign body sharp. Also, the ends of the safety pin were wide apart and pointing upwards.

\section{Case Presentation}

A one year old male child presented to the emergency with suspected ingestion of some foreign body four hours back followed by continuous dribbling of saliva, refusal of feeds and incessant cry. Patient was very irritable and unable to take even sips of water. X-Ray neck, chest and upper abdomen. Postero-anterior and lateral views revealed a wide open safety pin, with missing clip, in upper part of neck. Both the sharp ends were pointing upward. X-ray neck, chest and abdomen in a single film was repeated to exclude the presence of the clip of the safety pin inside the body from the nasopharynx to the abdomen. His chest examination revealed bilateral equal air entry with added sounds from upper airway probably because of aspiration of excess secretions in the oral cavity and the oropharynx.

Patient was prepared and emergency oesophagoscopy was done under general anaesthesia. As both the ends

1 - Department of ENT, Bankura Sammilani Medical

College, Bankura, West Bengal

2 - Department of ENT, Medical College, Kolkata

Corresponding author:

Dr Arvind Kumar Verma

email: dr.arv.verma@gmail.com 


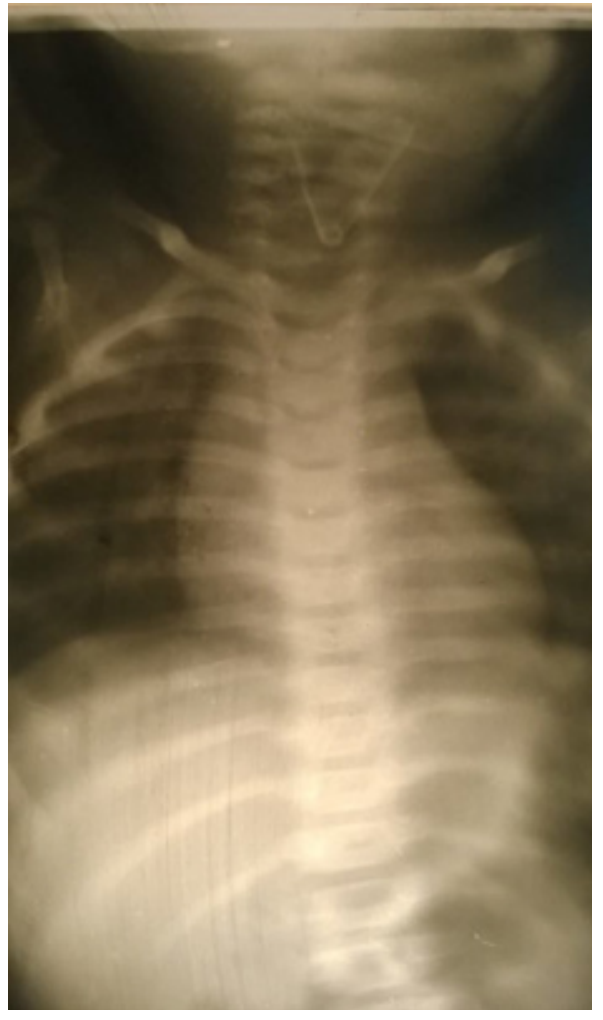

Fig. $1 \mathrm{X}$-ray neck postero-anterior view showing metallic foreign body

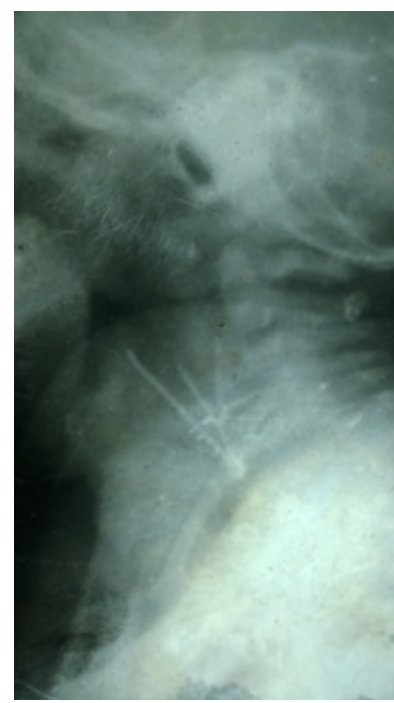

Fig. 2 X-Ray neck lateral view confirms FB to be in food passage were sharp, there was a definite risk of penetration of the oesophageal wall during attempted removal. So, instead of pulling the foreign body up with a foreign body holding forceps, the oesophagoscope was gently negotiated up to one end of the safety pin to bring it inside the lumen of the oesophagoscope.

After one sharp end could be secured against the barrel of the oesophagoscope, the disimpaction of the other end was comparatively safer and the other tip was also drawn inside the barrel of the oesophagoscope. Withdrawal of the oesophagoscope was done slowly, taking care not to lose the foreign body, as part of the broken safety pin remained inside the barrel of the oesophagoscope. Post-operative period was uneventful and patient was allowed oral feed after six hours and discharged on following day. Patient was doing well on

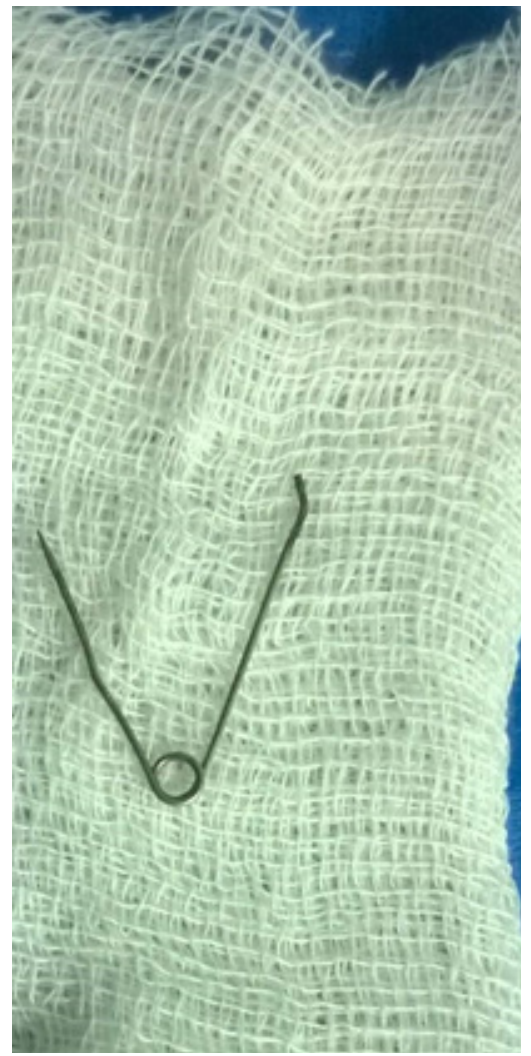

Fig. 3 The broken safety pin after removal 
follow up visit after seven days.

\section{Discussion}

Foreign body oesophagus is common in paediatric population but ingestion of such a foreign body in a child of one year is quite uncommon in our practice. The common site of impaction of accidentally ingested foreign bodies is the cricopharynx. ${ }^{5}$ In this case, the foreign body was impacted in the upper part of the oesophagus and its tips were projecting upwards. This patient presented with dysphagia which is a common symptom of foreign body oesophagus. Radiographs of the neck (postero-anterior and lateral views) are usually done to confirm the position of the foreign body, especially whether it is in the oesophagus or the respiratory tract. In this case, the radiograph revealed the foreign body to be in the upper aerodigestive tract at the level of the C3-C7 vertebrae. A sharp foreign body has increased risk of complications ${ }^{6,7}$ and a broken and open safety pin with its pointed ends upwards is a relatively difficult case. Rigid oesophagoscopy is the preferred modality in our institution to remove sharp foreign bodies from the upper digestive tract.

\section{Conclusion}

Foreign body ingestion in the paediatric population is common. Effort should be made by attending physicians to enquire into the details of events relating to ingestion of foreign body in order to arrive at an early and timely diagnosis to enable prompt treatment so as to prevent any complication. Broken foreign bodies necessitate a careful and thorough search to avoid retention of the missing part inside the body. Sharp foreign bodies pose an increased risk of oesophageal perforation and improvisations are often required in the surgical technique to tackle difficult situations.

\section{References}

1. Cheng W, Tam PK. Foreign-body ingestion in children: experience with 1,265 cases. J Pediatr Surg. 1999; 34(10):14721476.

2. Velitchkov NG, Grigorov GI, Losanoff JE, Kjossev KT. Ingested foreign bodies of the gastrointestinal tract: retrospective analysis of 542 cases. Worl J Surg. 1996; 20(8):1001-1005.

3. Yalçin S, Karnak I, Ciftci AO, Senocak ME, Tanyel FC, Büyükpamukçu N. Foreign body ingestion in children: an analysis of pediatric surgical practice. Pediatr Surg Int. 2007; 23(8):755-61

4. Selivanov V, Sheldon GF, Cello JP, Crass RA: Management of foreign body ingestion. Ann Surg. 1984; 199(2):187-191.

5. Singh A, Bajpai M, Panda SS, Chand K, Jana M, Ali A.Oesophageal foreign body in children: 15 years experience in a tertiary care paediatric centre. Afr J Paediatr Surg. 2014; 11(3):238-41.

6. Kay M, Wyllie R.Pediatric foreign bodies and their management Curr Gastroenterol Rep. 2005; 7(3):212-8.

7. Taylor RB. Oesophageal foregn bodies. Emerg Med Clin North Am.1987; 5(2):301-311. 